\title{
Comunicação
}

\section{Bacteremia após a colangiopancreatografia retrógrada endoscópica, com e sem procedimento terapêutico: freqüência, fatores associados e significado clínico}

\author{
G.M.R. Campos, B. Herani Filho, C.A.P. Pereira, A.M. De O. Machado, M.C.C. Baretta \\ Disciplina de Gastroenterol ogia Cirúrgica, Universidade Federal de São Paulo - E scola Paulista de Medicina, São Paulo, SP.
}

RESUMO - OвJ ETIVO. O objetivo do presente estudo foi avaliar a freqüência, os fatores associados e a manifestação clínica de bacteremia em pacientes submetidos à colangiopancreatografia retrógrada endoscópica (CPRE), associada ou não à realização de procedimento terapêutico.

Casuística. Foram analisadas prospectivamente 46 colangiopancreatografias retrógradas endoscópicas (CPREs) realizadas em 42 pacientes. Os pacientes foram divididos em três subgrupos na dependência da utilização de antibióticos, da presença de obstrução do ducto biliar e/ou pancreático e da realização de procedimentos terapêuticos.

Método. A pesquisa de bacteremia foi realizada mediante coleta de hemoculturas seriadas antes e após a CPRE. Foram utilizados, como meio para as hemoculturas, frascos tipo Bactec $^{\circledR}$, capazes de receber maiores volumes de sangue e com resinas para adsorção de antibióticos. A análise de positividade das hemoculturas foi realizada no sistema Bactec $9240^{\circledR}$, e a identificação das bactérias, por meio de rotina do Laboratório Central da instituição e com o sistema autoScan ${ }^{\circledR} /$ Mi croscan $^{\circledR}$.

\section{NTRODUÇÃO}

A colangiopancreatografia retrógrada endoscópica (CPRE) tem hoje ampla acei tação como método auxiliar no diagnóstico e no tratamento de várias doenças pancreáticas e do trato biliar. Entretanto, como qualquer procedimento invasivo, a CPRE não está isenta de complicações, que têm si do descritas em vários estudos, em freqüências que variam de 0,8 a $19,3 \%^{1-6}$.

As complicações mais graves e com mai or mortalidade são as infecciosas, como col angite e sepse ${ }^{7-9}$. Além do quadro de sepse que pode instal ar-se após uma CPRE, há a possibilidade da ocorrência de bacteremia, transitória ou não, durante e após a CPRE ${ }^{10-20}$. Segundo definiu a Society of Critical Care Medicine Consensus Conference ${ }^{21}$, bacteremia é a presença de bactérias viáveis no sangue e pode ocorrer de forma transitória, intermitente ou persistente, e ser ou não associada à sepse, na dependência do estado imunológico do paciente e do processo infeccioso desencadeante.
Resultados. Foi detectada bacteremia após sete exames; entretanto, em dois os microrganismos isolados foram considerados contaminantes. E m cinco exames ocorreu bacteremia verdadeira (freqüência, 10,9\%). Foram identificados os microrganismos: Streptococcus viridans, Corynebacterium sp., Enterobacter cloacae, Klebsiella oxytoca e Enterobacter aerogenes. Os epi sódios de bacteremia foram detectados com maior freqüência nas hemoculturas realizadas imediatamente após os exames $(p<0,05)$, e foram restritos aos pacientes que não estavam utilizando antibióti$\cos (p=0,0192)$. Não houve manifestação clínica dos episódios de bacteremia.

Conclusões. Concluiu-se que os epi sódios de bacteremia ocorreram exclusivamente nos pacientes que não estavam utilizando antibióticos e foram transitórios e completamente assintomáticos.

UNITERMOS: Pancreatocolangiografia retrógrada endoscópica. Bacteremia.

E $m$ pessoas normais a bacteremia, quando transitória, não deve deixar seqüelas, mas, em indivíduos com lesões cardíacas suscetíveis, a bactéria pode se alojar em valva cardíaca anormal ou lesada ou no endocárdio e no endotélio próximo a defeitos anatômicos congênitos e resultar em endocardite infecciosa ou endarterite ${ }^{22}$. Também há a possibilidade de resultar em infecção por contaminação de próteses ortopédicas e enxertos vasculare ${ }^{23}$ e iniciar complicações sépticas em pacientes severamente leucopênicos e naqueles imunocomprometidos ${ }^{24,25}$.

As recomendações da administração de antibioti copr ofilaxia antes de exames endoscópicos, tanto da American Heart Association (AHA) ${ }^{22}$ como da American Society for Gastrointestinal Endoscopy $(\mathrm{ASGE})^{27}$, procuram levar em conta as freqüências de bacteremia dos vários procedimentos e os tipos de bactérias responsáveis. Em alguns procedimentos como a escleroterapia de varizes de esôfago e dilatação esofágica, foi detectada freqüência elevada de bacteremia, com valores de até $72,2 \%{ }^{28-30}$, 
Tabela 1 - Freqüência de bacteremia após CPRE observada em trabalhos prospectivos

\section{Referência}

Lam et al. $(1977)^{10}$

Stray et al. (1978) $)^{11}$

Parker et al. (1979) ${ }^{12}$

Siegel et al. $(1979)^{13}$

Low et al. $(1980)^{14}$

Marsicano et al. $(1990)^{15}$

Sauter et al. (1990) ${ }^{16}$

Sontheimer et al. (1991)17

Kullman et al. (1992) ${ }^{18}$

Mollison et al. $(1994)^{19}$

Niederau et al. $(1994)^{20}$

Total

\begin{tabular}{cc} 
№ de exames & Com bacteremia (\%) \\
63 & 7,9 \\
25 & 0,0 \\
50 & 14,0 \\
50 & 4,0 \\
101 & 0,0 \\
22 & 13,6 \\
100 & 9,0 \\
25 & 48,0 \\
194 & 19,1 \\
179 & 5,0 \\
100 & 4,0 \\
909 & 9,7 \\
\hline
\end{tabular}

e tem indi cação de profilaxia, segundo as recomendações da AHA. Durack et al. ${ }^{26}$, em artigo de revisão sobre endocardite bacteriana, citam que a freqüência de bacteremia após CPRE é, em média, de $5 \%$ ( 0 a $6 \%$ ); entretanto, em trabalhos prospectivos, essa freqüência varia de 0 até $48 \%$ (tabela 1 ).

Nos trabalhos prospectivos, acima citados, sobre bacteremia após CPRE, além da freqüência, varia o ti po de bactéria encontrada nas hemocul turas. A diferença dos resultados deve-se à somatória de fatores inerentes ao método de detecção (diferenças no volume e número das amostras de sangue para as hemoculturas; diferenças nas técnicas de col eta e cultura do sangue; diferenças no sistema utilizado para detecção do crescimento bacteriano no meio de cultura) e aos parâmetros utilizados para análise dos resultados ${ }^{31-33}$.

As condições de trabalho, de pessoal e de material médico-hospitalar utilizados nos procedimentos endoscópicos (especificamente a CPRE) podem ter influência sobre a freqüência de bacteremia. Os índices relatados na literatura consultada podem diferir da encontrada em nosso meio.

O objetivo do presente estudo foi avaliar a freqüência, os fatores associados e a manifestação clínica de bacteremia em pacientes submetidos a CPRE com e sem procedimento terapêutico, com a utilização de frascos capazes de receber maiores volumes de sangue, com resinas para adsorção de anti biótico e aparel ho automatizado para análise das hemoculturas.

\section{CASUÍSTICA}

No período de 12 de agosto a 16 de dezembro de 1994, 56 pacientes foram submetidos a 65 CPRES no Setor de Endoscopia Digestiva da Disciplina de Gastroenterologia Cirúrgica do Hospital São Paulo da Universidade Federal de São Paulo (UNIFESP),
Tabela 2 - Indicações para a realização da CPRE

\begin{tabular}{|lc|}
\hline \multicolumn{1}{|c|}{ Indicação } & N $(\%)$ \\
Coledocolitíase + colelitíase & $11(23,9)$ \\
Pancreatite aguda biliar & $10(21,7)$ \\
Icterícia pregressa + colelitíase & $6(13,0)$ \\
Coledocolitíase residual & $6(13,0)$ \\
Controle papiloesfincterotomia & $3(6,5)$ \\
Coledocolitíase recorrente & $2(4,4)$ \\
Pancreatite crônica & $2(4,4)$ \\
Neoplasia da cabeça do pâncreas & $2(4,4)$ \\
Síndrome de icterícia obstrutiva & $2(4,4)$ \\
Síndrome pós-colecistectomia & $1(2,2)$ \\
Estenose via biliar & $1(2,2)$ \\
Total & $46(100,0)$ \\
\hline
\end{tabular}

Escola Paulista de Medicina (EPM). Foram avaliados prospectivamente e sem interferir na rotina de serviço do Setor de Endoscopia e nas orientações médicas dos responsáveis pelos pacientes. O protocolo da pesquisa foi previamente aprovado sem restrições pela Comissão de Ética dessa instituição.

Os critérios de exclusão foram:

1) Recusa em participar da pesquisa após esclarecimento da rotina de avaliação.

2) Pacientes com outras causas possíveis de bacteremia que pudessem fornecer falsos resultados positivos, tais como diagnóstico clínico de colangite aguda; com possíveis fontes de infecção que não nas vias biliares e no pâncreas; presença de cateteres urinários, cateteres venosos centrais e/ou drenagem externa da via biliar por tubo T.

3) Impossibilidade técnica de venopunção padronizada para a coleta de sangue para as hemoculturas.

4) I mpossibilidade técnica de injeção de contraste no ducto biliar ou pancreático durante a CPRE.

No grupo inicial, 14 pacientes, submetidos a 19 CPRES, foram excluídos da pesqui sa por apresentarem algum dos critérios de exclusão.

Os 42 pacientes restantes realizaram um total de 46 CPRES, que compõem o montante de exames endoscópicos avaliados neste estudo.

A idade média dos pacientes foi de 52,90 anos, variando de 13 a 93 anos. Trinta e seis exames $(78,3 \%)$ foram realizados em pacientes do sexo feminino e dez (21,7\%), em pacientes do sexo masculino.

As indicações para realização das CPRES são apresentadas de forma agrupada na tabela 2 .

Os exames for am real izados nas sal as do Servi ço de Radiologia da UNIFESP/EPM, equipadas com aparelhos de radioscopia. Foram utilizados os apareIhos videoduodenoscópios Pentax ${ }^{\circledR}$ ED-3401 e ED3410. Os cuidados com a descontaminação dos endoscópios e acessórios seguiram a rotina do 
Tabela 3 - Distribuição dos pacientes nos subgrupos avaliados

\begin{tabular}{|lcc|}
\hline \multicolumn{1}{|c|}{ Subgrupo } & Com & Sem \\
& $\mathbf{N}(\%)$ & $\mathbf{N}(\%)$ \\
Antibiótico & $24(52,2 \%)$ & $22(47,8 \%)$ \\
Obstrução & $21(45,7 \%)$ & $25(54,3 \%)$ \\
Procedimento & $25(54,3 \%)$ & $21(45,7 \%)$ \\
\hline
\end{tabular}

Tabela 4 - Diagnósticos das CPREs

\begin{tabular}{|lc|}
\hline \multicolumn{1}{|c|}{ Diagnósticos } & № $(\%)$ \\
Colelitíase & $15(32,6)$ \\
Colelitíase e coledocolitíase & $13(28,2)$ \\
Coledocolitíase & $8(17,4)$ \\
Normal & $3(6,5)$ \\
Neoplasia de pâncreas & $2(4,3)$ \\
Divertículo justapapilar & $1(2,2)$ \\
Papilite & $1(2,2)$ \\
Pseudocisto de pâncreas & $1(2,2)$ \\
Estenose de via biliar & $1(2,2)$ \\
Pancreatite crônica & $1(2,2)$ \\
Total & $46(100,0)$ \\
\hline
\end{tabular}

Setor de Endoscopia e atendem as recomendações mais recentes da $\mathrm{ASGE}^{34}$. O tempo de duração dos exames variou de 10 a 135 minutos, com média de 39,89 minutos. Em todos os exames houve cateterização, com injeção de contraste na via biliar e/ou no ducto pancreático. $\mathrm{O}$ vol ume de contraste utilizado variou de 15 a $75 \mathrm{~mL}$, com média de $32,82 \mathrm{~mL}$. E m 25 exames (54,3\%) foi realizado al gum tipo de procedimento terapêutico (papiloesfincterotomia completa ou incompleta e/ou instrumentação da via biliar ou pancreática); em 21 (45,7\%), somente exame diagnóstico.

Os pacientes foram distribuídos, para posterior análise, em subgrupos, na dependência da utilização de anti biótico (administração até 14 dias antes da data do exame ou uso na ocasião da real ização da CPRE), da presença de obstrução parcial ou total da via biliar e/ou ducto pancreático e da realização de procedimento terapêutico. A distribuição resultou em subgrupos, com número semel hante de pacientes (tabela 3), o que permitiu análise estatística adequada da influência dessas variáveis sobre os resultados da pesquisa.

$\mathrm{Na}$ tabela 4 são apresentados sumariamente os diagnósticos endoscópi cos e/ou radi ológicos da série.

H ouve seis complicações relacionadas aos 46 exames endoscópicos (13,0\%); todas ocorreram em pacientes nos quais foi realizado algum procedimento terapêutico. A complicação mais freqüente foi o sangramento (três exames, 6,5\%). A col angite aguda ocorreu após dois exames (4,3\%). Esses pacientes estavam sob antibioticoterapia durante o exame, mas não houve drenagem efetiva da via biliar. Perfuração retroduodenal ocorreu após um CPRE $(2,2 \%)$.

A mortalidade relacionada ao procedimento endoscópico foi de 2,2\% (em paciente no qual ocorrera perfuração retroduodenal durante a CPRE).

\section{MÉ TODO}

Foram col hidas de todos os pacientes seis amostras de 20mL de sangue cada; duas antes da real ização das CPRES e quatro após.

As amostras de sangue foram obtidas por punção de veia superficial do antebraço esquerdo com cateter tipo Gelcro número 20G x 1누" (Safelet Cath $^{\circledR}$, Nipro Medical Industries, Ltd., J apão), após anti-sepsia da pele com álcool etílico a $70 \%$ e P.V.P.I. tópico a $10 \%$. O cateter foi fixado ao antebraço do paciente e conectado a uma torneira de 3 vias (Nipro Stopcock - 3 Way Luer Lock ${ }^{\circledR}$, Nipro Medical Industries, Ltd., J apão). O interior do conjunto era completamente preenchido por uma solução de heparina e água destilada estéreis em diluição de 1:5.000 e fechados com cuidados adequados para evitar contaminação, para permitir posterior coleta de novas amostras de sangue. Antes de cada nova coleta eram retirados $3 \mathrm{~mL}$ de sangue pelo conjunto Gelcro/Torneira de três vias em uma seringa em separado que era desprezada, para certificarmo-nos de que a coleta era de sangue venoso e não do interior do conjunto.

E $m$ todas as col etas o sangue era inoculado em partes iguais $(10 \mathrm{~mL})$, em dois frascos para hemocultura (para germes aeróbios e anaeróbios).

As coletas anteriores às CPRES tiveram intervalo de 15 minutos entre si. Essas amostras tiveram o intui to de demonstrar que os pacientes não tinham bacteremia anterior ao exame.

As coletas posteriores às CPRES foram feitas sempre logo após a retirada do endoscópio (tempo zero), e 5, 15 e 30 minutos após o tér mino do exame endoscópico, observada a técnica descrita acima.

As amostras foram denominadas indicando o tipo de frasco (AE - aeróbio ou AN - anaeróbio), seguido por um número que indica o tempo de coleta; como, por exemplo: AE.0 - hemocultura para germes aeróbios no tempo zero; AN.15 hemocultura para germes anaeróbios aos $15 \mathrm{minu}$ tos após o término da CPRE.

Os frascos utilizados como meio para as hemoculturas foram do tipo Bactec ${ }^{\circledR}$ (Becton Dickinson and Company), com resina para adsorção de antibióticos - Bactec Plus Aerobic/ $\mathrm{F}^{\circledR}$ e Bactec Plus Anaerobic/ $\mathrm{F}^{\circledR}$, para todos os pacientes. 


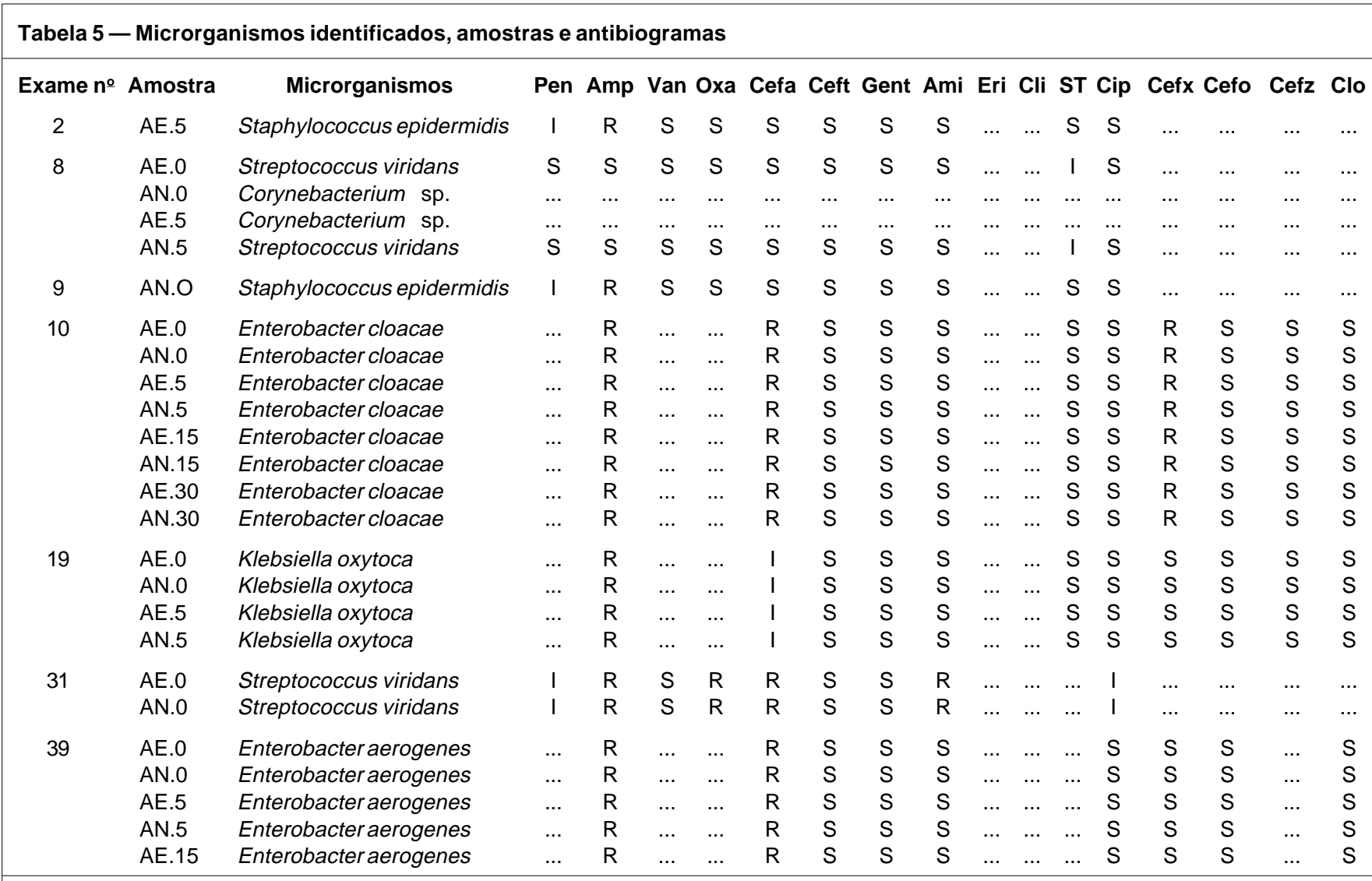

$\mathrm{S}=$ sensível; $\mathrm{I}$ = intermediário; $\mathrm{R}$ = resistente; $\ldots$ = não realizado; Pen = penicilina; $\mathrm{Amp}=$ ampicilina; Van = vancomicina; Oxa = oxacilina; Cefa = cefalotina; Ceft = ceftriaxona; Gent = gentamicina; $\mathrm{Ami}=$ amicacina; Eri = eritromicina; $\mathrm{Cli}=$ clindamicina; $\mathrm{ST}=$ sulfametaxol + trimetoprima; Cip = ciprofloxacina; Cefx = cefoxitina; Cefo = cefotetan Cefz $=$ ceftazidime $;$ Clo = cloranfenicol.

Os frascos de cultura eram imediatamente encaminhados para o Laboratório Central da UNIFESP/EPM e incubados para leitura na estante do sistema Bactec $9240^{\circledR}$ (Becton Dickinson and Company), em temperatura constante de $35^{\circ} \mathrm{C}$ e em agitação constante, onde permaneciam por cinco dias, no máximo.

O sistema Bactec $9240^{\circledR}$ é aparelho designado para detecção rápida e completamente automatizada de bactérias e fungos em hemoculturas dos frascos do tipo Bactec ${ }^{\circledR}$. O princípio de detecção do sistema é baseado na produção de $\mathrm{CO}_{2}$ pel as bactérias. A análise é realizada de 10 em 10 minutos, ininterruptamente, durante as 24 horas, mediante sensor automático não-invasivo.

Se a leitura do sistema Bactec $9240^{\circledR}$ indicasse a presença de bactérias, era realizada bacterioscopia pelo Gram, e o sangue semeado em duas placas de Petri, uma com ágar-sangue e outra com ágar-chocolate enriquecido, que eram levadas a uma estufa de $\mathrm{CO}_{2}$ por 24 horas a $36,6^{\circ} \mathrm{C}$. Se não houvesse formação de colônias, eram feitos repiques a cada 24 horas até 72 horas. Se após essas 72 horas não houvesse formação de colônias, o resultado era considerado negativo. Ao haver formação de colônias, realizava-se a identificação da bactéria, conforme a rotina manual do Laboratório Central, e em paralelo com o sistema autoScan ${ }^{\circledR}$ Microscan ${ }^{\circledR}$ (Baxter Instruments).

Se a leitura do sistema Bactec $9240^{\circledR}$ fosse negativa, até após cinco dias, os frascos Bactec $^{\circledR}$ eram desprezados e o resultado da hemocultura considerado negativo.

O segui mento dos pacientes para a identificação de complicações e evolução foi realizado mediante avaliação clínica diária, com a observação de sinais vitais por 72 horas, no mínimo. Foram considerados como sintomáticos os pacientes nos quais se detectou temperatura $\geq 37,8^{\circ} \mathrm{C}$ e/ou calafrios. Colangite foi definida como o aparecimento após a CPRE de icterícia, temperatura $\geq 37,8^{\circ} \mathrm{C}$, calafrios e dor no quadrante superior direito do abdome.

Para análise dos resultados foram aplicados os seguintes testes:

1) Teste $G$ de Cochran ${ }^{35}$ para estudar a detecção de bacteremia entre os tempos de coleta. 
2) Teste de Mann-Whitney com aproximação à curva normal ${ }^{35}$, para comparar os grupos com e sem bacteremia, com e sem anti biótico e com e sem procedimento, para as diferentes variáveis estudadas.

3) Teste exato de Fischer ${ }^{35}$ para estudar as associações existentes entre as variáveis estudadas.

Em todos os testes fixou-se em 0,05 ou $5 \%$ ( $\alpha \leq$ $0,05)$ o nível de rejeição da hipótese de nulidade, assinalados com asterisco os valores significantes.

\section{RESULTADOS}

Todas as hemoculturas de coleta anterior às CPRES, em todos os pacientes, foram negativas, isto é, não se detectou bacteremia antes dos exames.

$\mathrm{N}$ as hemoculturas realizadas após as 46 CPRES, foi constatado crescimento bacteriano após sete (15,2\%); entretanto, em dois, os microrganismos identificados (Staphylococcus epidermidis) foram considerados contaminantes e isolados em somente um de cada 12 frascos da rotina de col eta de cada exame (exame no 2, AE.5 e exame no 9, AN.0). Nos outros cinco exames, houve detecção de crescimento bacteriano sempre em mais de um frasco e foram considerados como decorrentes do procedimento endoscópico, o que resulta freqüência de bacteremia de $10,9 \%$ na nossa casuística.

$\mathrm{Na}$ tabela 5 são apresentados os microrganismos identificados, o número do exame, as amostras e o antibiograma respectivos.

Houve diferença significante entre os tempos de coleta, na detecção de bacteremia: mais freqüente no tempo zero e com decréscimo aos 30 minutos, como demonstrado na tabela 6.

As hemoculturas que indicavam bacteremia após as CPRES foram restritas ao grupo de pacientes que não estavam submetidos à anti bioticoterapia ( $p=0,0192)$, como demonstrado na tabela 7 .

F oi demonstrado que a leucometria, a hemoglobinemia, a albuminemia, o tempo dos exames e o volume de contraste utilizado durante as CPRES do grupo com antibiótico eram semel hantes aos do grupo sem antibiótico (teste de Mann-Whitney).

Não houve associação de bacteremia à idade, ao sexo, à presença de doenças associadas, à leucometria, à hemoglobinemia, à albuminemia, ao tempo de exame e ao vol ume de contraste utilizado durante as CPRES.

Ao se analisar a freqüência de bacteremia na série e sua associ ação com a realização de procedimentos terapêuticos, nota-se que quatro episódi os de bacteremia ocorreram após as 25 CPRES (freqüência de $16,0 \%$ ) com procedimento terapêutico e
Tabela 6-Tempo decorrente entre o exame e coleta de sangue para hemoculturas e detecção de bacteremia

\begin{tabular}{|c|c|c|c|c|c|}
\hline Exame no & Antes & $0 \mathrm{~min}$ & $5 \mathrm{~min}$ & $15 \mathrm{~min}$ & $30 \mathrm{~min}$ \\
\hline 8 & $\ldots$ & + & + & $\ldots$ & $\ldots$ \\
\hline 10 & $\ldots$ & + & + & + & + \\
\hline 19 & $\ldots$ & + & + & $\ldots$ & $\ldots$ \\
\hline 31 & $\ldots$ & + & $\ldots$ & $\ldots$ & $\ldots$ \\
\hline 39 & $\ldots$ & + & + & + & $\ldots$ \\
\hline Total & 0 & 5 & 4 & 2 & 1 \\
\hline$\%$ & 0,0 & 100,0 & 80,0 & 40,0 & 20,0 \\
\hline \multicolumn{6}{|c|}{$\begin{array}{l}\ldots=\text { hemocultura negativa; }+=\text { hemocultura positiva. } \\
\text { Teste } G \text { de Cochran } \\
\text { G calculado }=13,76^{\star} ; G \text { crítico }=9,49\end{array}$} \\
\hline
\end{tabular}

Tabela 7 - Bacteremia em pacientes com e sem antibiótico

\begin{tabular}{|lcccr|}
\hline & \multicolumn{3}{c}{ Bacteremia } & \\
\cline { 2 - 5 } & Com & Sem & Total & $\%$ \\
Com antibiótico & 0 & 24 & 24 & 0,0 \\
Sem antibiótico & 5 & 17 & 22 & 22,7 \\
Total & 5 & 41 & 46 & 10,9 \\
\hline Teste exato de Fischer & $-p=0,0192$ * ou $1,92 \%$ com < sem. \\
\hline
\end{tabular}

somente um episódio de bacteremia ocorreu após as 21 CPRES (freqüência de 4,8\%), sem procedimento terapêutico; entretanto, esses valores não obtiveram diferença significante (teste exato de Fischer $-p=0,2326$ ). No grupo de 22 pacientes sem antibioticoterapia, a freqüência de bacteremia foi de $30,8 \%$ naqueles com procedimento terapêutico, e de $11,1 \%$ nos pacientes sem procedimento (teste exato de Fischer $-p=0,2932$ ).

O tempo dos exames dos pacientes com procedimento terapêutico $(47,4$ minutos) foi significativamente maior do que o dos exames sem procedimento terapêutico (30,9 minutos) (teste de MannWhitney - Z crítico $=1,96$ - com $x$ sem $-Z=2,18$ * - com $>$ sem). $O$ volume de contraste utilizado nos exames com procedimento terapêutico foi semeIhante ao volume utilizado nos que não houve.

A presença de obstrução, parcial ou total, da via biliar e/ou pancreática, também não foi fator associado a maior freqüência de bacteremia em nossa casuística. Bacteremia foi detectada em 2 de 21 pacientes (9,5\%) com obstrução, e em 3 de 25 $(12,0 \%)$ sem obstrução (teste exato de Fischer - p $=0,5849$ ).

Em todos os pacientes nos quais foi detectada bacteremia, não houve manifestação clínica, e na evolução, até 72 horas, também não houve repercussões sépticas ou aparecimento de quadro de colangite. Todos tiveram evolução satisfatória, sem apresentar quaisquer complicações.

Os dois episódios de colangite após as CPREs 
ocorreram em pacientes nos quais não foi detectada bacteremia pelo método.

\section{DISCUSSÃO}

Este é o primeiro estudo, em nosso meio, a analisar prospectivamente a ocorrência de bacteremia após a CPRE. Da literatura mundial consultada, constatou-se que é o único estudo que segue rigorosamente as mais recentes orientações para que se obtenha resultados confiáveis em análise de hemoculturas. A pesquisa foi realizada sem interferir em toda a rotina de atendimento, para que se pudessem obter resultados representativos da freqüência de bacteremia após CPRE em um serviço ativo de endoscopia digestiva de hospital escola.

Todos os estudos sobre o tema ${ }^{10-20}$ optaram por método similar para a coleta de sangue para as hemoculturas, por venopunção única em tempos predeterminados. Entretanto, à exceção das coletas prévias às CPRES, que foram realizadas em todos os exames, há diferenças entre os tempos escolhidos pelos autores para a coleta de sangue após o início do exame endoscópico. Visto que a bacteremia, desencadeada pelos exames endoscópicos, é geralmente transitória ${ }^{36}$, optou-se, neste estudo, em colher as amostras imediatamente após a CPRE e em três tempos próximos ao exame (5, 15 e 30 minutos). A col eta de maior número de hemoculturas preenche um dos requisitos para aumentar a sensibilidade do método e também pode auxiliar na diferenciação entre bacteremia verdadeira e contaminação ${ }^{32}$. Também o volume total de $20 \mathrm{~mL}$ de sangue por tempo está de acordo com as recomendações para aumentar a sensibilidade das hemoculturas $32,37-39$.

Além de poder reduzir a concentração e neutralizar a ação de antibióticos no meio de cultura, as resinas podem melhorar os índices de recuperação de bactérias em pacientes que não estejam recebendo antibióticos, uma vez que a agitação constante do meio, na presença de resinas, resulta em lise dos eritrócitos e leucócitos, o que cria novas superfícies às quais as bactérias podem aderir, tornando o meio melhor para reprodução bacteriana e resultando em maiores índices de detecção $0^{40}$. Nenhum estudo que analisa bacteremia em relação à CPRE utilizou frascos capazes de receber maiores volumes e com resinas para adsorção de antibióticos.

Neste estudo, foi utilizado o sistema Bactec $9240^{\circledR}$, que é o mais recente sistema automatizado disponível. Esse sistema tem demonstrado resultados favoráveis, quando comparado a outros ${ }^{40,41}$, além de apresentar todas as vantagens de um siste- ma automatizado: servir ao mesmo tempo como incubador, agitador e sistema de detecção; apresentar tempo menor de detecção de positividade das hemoculturas; propiciar resultados mais confiáveis pela ausência de manipulação após a incubação e pela monitoração contínua, e capaci dade de acomodar grande quantidade de frascos $\cos ^{41-44}$.

Neste estudo, foi detectada bacteremia após sete exames; entretanto, foi considerado que, em dois, o microrganismo identificado (Staphylococcus epidermidis) não representava bacteremia verdadeira. A bacteremia que se segue ao procedimento endoscópico é, geralmente, causada por microrganismos provenientes do sistema digestivo e da flora bucal, cujos principais representantes são bacilos gram-negativos, como Escherichia coli, Enterobacter sp. e Klebsiella sp., entre outros (sistema digestivo), e o Streptococcus viridans (flora bucal) $)^{22,31,45-47}$. O Staphylococcus epidermidis, além de não representar a bactéria que clinicamente se espera encontrar, é consi derado o contaminante mais comum em hemoculturas, principalmente quando sua identificação se faz somente em um frasco da série ${ }^{32}$. É somente o isolamento repetido de linhagens do Staphylococcus epidermidis com marcadores idênticos (espécie, antibiograma, análise do padrão nuclear) o considerado como indicativo de bacteremia verdadeira ${ }^{37}$. Quando detectado após procedimentos endoscópicos, a origem mais provável é do endoscópio e/ou dos acessórios contaminados pelo microrganismo ${ }^{48}$.

Nesta pesquisa, foram identificados microrganismos considerados como responsáveis por episódios de bacteremia verdadeira em cinco pacientes, correspondendo a uma freqüência de bacteremia da série de $10,9 \%$. Os microrganismos Streptococcus viridans e Corynebacterium sp. têm origem muito provável na flora bacteriana da cavidade oral. J á os microrganismos Enterobacter cloacae, Klebsiella oxytoca e Enterobacter aerogenes têm sua origem provável na flora bacteriana do sistema digestivo ou do conduto biliopancreático. Essas são suspeitas baseadas somente em dados epidemiológicos encontrados na literatura sobre o tema $22,45-47,49$.

Durante o período de estudo, não foi diagnosticada bacteremia por mi crorganismos com origem provável em endoscópios e acessórios contaminados (Pseudomonas aeruginosa, Salmonella sp., Serratia sp., Staphylococcus aureus, Staphylococcus epidermidis). I sso sugere que a metodologia de descontaminação atualmente empregada é satisfatória, mas para conclusões definitivas a esse respeito seria necessária anál ise mais direcionada, com envolvimento do estudo bacteriológico 
dos aparel hos e amostra maior de pacientes, pois a infecção por tais ti pos de mi crorganismos se faz em episódi os epidêmicos isol ados ${ }^{50}$.

A detecção de bacteremia foi mais freqüente no tempo zero, ou seja, logo após a retirada do endoscópio, com decréscimo significante aos 30 minutos; isso bem demonstra que a bacteremia, quando ocorreu, esteve relacionada à realização do exame e foi transitória.

Ficou demonstrado que os resultados dos antibiogramas dos microrganismos detectados em cada exame foram idênticos, o que também vêm ao encontro do raciocínio de que esses episódios foram de bacteremia verdadeira.

Todos os cinco episódios de bacteremia ocorreram nos pacientes do grupo que não estava utilizando antibióticos, que foi significativamente maior $(22,7 \%)$, quando comparado ao grupo que estava sob antibioticoterapia ( $0 \%)(p=0,0192$ ou $1,92 \%)$. Houve intenção em demonstrar que os dois grupos (com e sem antibiótico) eram semel hantes entre si na comparação dos resultados de alguns exames laboratoriais (leucometria, hemoglobinemia e albuminemia), e que não houve outras variáveis responsáveis (tempo de exame e volume de contraste) para essa importante diferença. Na literatura consultada, dois autores ${ }^{16,20}$ analisaram prospectivamente grupos de pacientes com e sem antibióticos; não demonstraram ser esses grupos semel hantes entre si nos aspectos que podem interferir nos resultados, como foi por nós realizado. Demonstraram maior freqüência de bacteremia nos pacientes que não receberam antibióticos.

Sauter et al. ${ }^{16}$ não encontraram maior freqüência de bacteremia após CPRES com procedimentos terapêuticos, quando comparadas às diagnósticas $(16,7 \% \times 15,6 \%)$. Kullman et al. ${ }^{18}$ relataram maior freqüência, quando realizaram procedimentos terapêuticos ( $27 \% \times 15 \%)$; entretanto, o nível de significância relatado para esse achado é de $10 \%$. Mollison et al. ${ }^{19}$ demonstraram essa associação com procedimentos terapêuticos $(p=0,015)$ e também obstrução biliar $(p=0,045)$. Em nossa casuística, a freqüência de bacteremia nos exames em que se realizou algum procedimento terapêutico, ou não, foi de $16,0 \%$ e de $4,8 \%$, respectivamente. Esse resultado sugere aparente associação entre bacteremia e realização de procedimentos terapêuticos; entretanto, com o tamanho dessa amostra, os valores não tiveram diferença com significância estatística ( $p=0,2326$ ou 23,26\%).

Em nosso estudo, a freqüência de bacteremia detectada nos pacientes sem antibioticoterapia e com procedimento terapêutico $(30,8 \%)$ se aproxima dos mais elevados citados anteriormente e sugere necessidade da avaliação rotineira de indicação de antibioticoprofilaxia ao se tratar desse subgrupo de pacientes.

Em nossa pesquisa, não foi demonstrada associação entre bacteremia e presença de obstrução, parcial ou total, do ducto biliar e/ou pancreático, como demonstrado por Lam et al. ${ }^{10}$, Parker et al. ${ }^{12}$ e Mollison et al. ${ }^{19}$. Esses autores sugerem que tal associação seja decorrência da colonização da bile estagnada por bactérias e que, quando a via biliar é submetida a aumento de pressão por injeção de contraste ou há instrumentação, pode ocorrer bacteremia com maior facilidade.

Todos os episódios de bacteremia detectados foram assintomáticos e os pacientes evoluíram satisfatoriamente, configurando bacteremia transitória, como também descrito em alguns estu$\operatorname{dos}^{10,12,13,16,19,20}$. Alguns autores demonstram a mesma ocorrência; mas isto não é a regra, pois também há descrição de episódios de bacteremia em pacientes que apresentaram colangite e sepse associadas $^{10,12,16,19,20}$.

Em dois pacientes da nossa casuística foi detectada bacteremia por Streptococcus viridans e, em três, por bacilos gram-negativos. Fica clara a necessidade de se obter avaliação clínica adequada, previamente à realização do exame endoscópico, nos pacientes com doença cardíaca já definida, imunossuprimidos e/ou com próteses, para se optar pela utilização de antibiótico(s) profilático(s). Segundo a ASGE ${ }^{27}$, Dajani et al. ${ }^{22}$ e Durack ${ }^{26}$, um dos fatores que pesa para indicação do uso da antibioticoprofilaxia, em pacientes selecionados, é a incidência de bacteremia após os vários exames. Acreditamos, portanto, que a CPRE pode ser colocada como exame endoscópico em que o risco da ocorrência de bacteremia é el evado.

\section{CONCLUSÃO}

Os resultados da presente pesquisa permitem concluir que, nesta amostra, os epi sódios de bacteremia ocorreram exclusivamente no subgrupo de pacientes que não estavam utilizando antibióticos; foram transitórios e completamente assintomáticos.

\section{AGRADECIMENTOS}

Os autores agradecem aos Drs. Neil Ferreira Novo e Yara J uliano, do Departamento de Bioestatística da UNIFESP/EPM, pelas orientações e realização das análises estatísticas deste trabalho.

Este trabalho é parte da tese de Mestrado apresen- 
tada ao Curso de Pós-Graduação da Disciplina de Gastroenterologia Cirúrgica da UNIFESP/EPM. Apoio da Coordenadoria de Aperfeiçoamento de Pessoal de Nível Superior (CAPES).

\section{SUMMARY}

Bacteremia after endoscopic retrograde cholangiopancreatography with or without therapeutic procedure: frequency, associated factors and clinical manifestations

Purpose. To determine the frequency, associate factors and clinical features of bacteremia in patients undergoing endoscopic retrograde cholangiopancreatography (ERCP), with or without therapeutic procedures.

Methods. Prospectively, 42 consecutives patients undergoing 46 endoscopic retrograde cholangiopancreatographies (ERCPS) from August to December 1994 were analyzed. The search for bacteremia was done by drawing 6 blood samples for cultures from peripheral blood. Two blood samples were collected before the ERCP and 4 of them after. The bottles used for cultures were Bactec $^{\mathrm{TM}}$ bottles. The bottles were incubated in the Bactec $9240^{\mathrm{TM}}$ system, and eventual bacteria detect were identificated by the manual routine of the laboratory and also with the autoScan ${ }^{\mathrm{TM}} / \mathrm{Mi}$ croscan $^{\text {TM }}$ system.

Results. All blood cultures obtained before the ERCPS were negatives. Bacteremia were detected after 7 endoscopic procedures. In two episodes of bacteremia, the microorganism identified (Staphylococcus epidermidis) was considered to be a contaminant. The other 5 episodes of bacteremia were considered true bacteremia (frequency $10.9 \%)$, and the microorganisms identified were: Streptococcus viridans, Corynebacterium sp., Enterobacter cloacae, Klebsiella oxytoca and E nterobacter aerogenes. This episodes were more frequent in the blood cultures obtained immediately after the ERCPS $(p<0.05)$, and occurred exclusively in the patients who were not receiving antibiotics $(p=0.0192)$. Clinical manifestation of the episodes of bacteremia were not detected.

Conclusion. The episodes of bacteremia occurred exclusively in the patients who were not receiving antibiotics, were transient and completely no symptomatic. [Rev Ass Med Brasil, 1997; 43(4): 326-34.]

KEY WORDS: Endoscopic retrograde cholangiopancreatographies. Bacteremia.

\section{REFERÊNCIAS BIBLIOGRÁFICAS}

1. Arrowsmith J B, Gerstman BB, Fleischer DE, Benjamin SB. Results from the American Society for Gastrointestinal Endoscopy/U.S. Food and Drug Administration collaborative study on complication rates and drug use during gastrointestinal endoscopy. Gastrointest Endosc 1991; 37(4): 421-7.

2. Cotton PB, Lehman G, Vennes J et al. Endoscopic sphincterotomy complications and their management: an attempt at consensus. Gastrointest Endosc 1991; 37(3): 383-93.

3. Lambert ME, Betts CD, Hill J et al. Endoscopic sphincterotomy: the whole truth. Br J Surg 1991; 78(4): 473-6.

4. Pasanen $P$, Partanen K, Pikkarainen $P$ et al. Complications of endoscopic retrograde cholangiopancreatography in jaundiced and cholestatic patients. Ann Chir Gynaecol 1992; 81(1): 28-31.

5. Lenriot J P, Le Neel J C, Hay J M et al. Cholangio-pancréatographie rétrograde et sphinctérotomie endoscopique pour lithiase biliaire: évaluation prospectiveen milieu chirurgical. Gastroenterol Clin Biol 1993; 17(4): 244-50.

6. Thornton J, Axon A. Towards safer endoscopic retrograde cholangiopancreatography. Gut 1993; 34(6): 721-4.

7. Benchimol D, Bernard J L, Mouroux J , Dumas R et al. Infectious complications of endoscopic retrograde cholangiopancretography managed in a surgical unit. Int Surg 1992; 77(4): 270-3.

8. Devière J, Motte S, Dumonceau J M et al. Septicemia after endoscopic retrograde cholangiopancreatography. Endoscopy 1990; 22(2): 72-5.

9. Novello $P$, Hagege $H$, Ducreux $M$ et al. Scepticémies après cholangiopancréatographie rétrograde endoscopique: facteurs derisque et antibioprophylaxie. Gastroenterol Clin Biol 1993; 17(12): 897-902.

10. Lam SK, Tsui J KC, Cjan PKW, Wong KP, Ong GB. How often does bacteraemia occur following endoscopic retrograde cholangiopancreatography (ERCP)? E ndoscopy 1977; 9(4): 231-4.

11. Stray N, Midtvedt T, Valnes $K$ et al. Endoscopy related bacteraemia. Scand J Gastroenterol 1978; 13(3): 345-7.

12. Parker HW, Geenen J E, Bjork J T, Stewart ET. A prospective analysis of fever and bacteremia following ERCP. Gastrointest Endosc 1979; 25(3): 102-3.

13. Siegel J H, Berger SA, Sable RA, Ho R, Rosenthal WS. Low incidence of bacteremia following endoscopic retrograde cholangiopancreatography (ERCP). AmJ Gastroenterol 1979; 71(5): 465-8.

14. Low DE, Micflikier AB, Kennedy J K, Stiver HG. Infectious complications of endoscopic retrograde cholangiopancreatography: a prospective assessment. Arch Intern Med 1980; 140: 1.076-7.

15. Marsicano LJ , Serrano N, Urrestarazu MI, Poleo J R. Colangiopancreatografía retrógrada: incidencia de bacteremia. GEN 1990; 44(1): 28-34.

16. Sauter G, Grabein B, Huber $G$ et al. Antibiotic prophylaxis of infectious complications with endoscopic retrograde cholangiopancreatography: a randomized controlled study. Endoscopy 1990; 22(4): 164-7.

17. Sontheimer J, Salm R, Friedrich G, Wahlert J V, Pelz K. Bacteremia following operative endoscopy of upper gastrointestinal tract. Endoscopy 1991; 23(2): 67-72.

18. Kullman $E$, Borch $K$, Lindström $E$ et al. Bacteremia following diagnostic and therapeutic ERCP. Gastrointest EndosC 1992; 38(4): 444-9.

19. Mollison LC, Desmond PV, Stoclkman KA et al. A prospective study of septic complications of endoscopic retrograde cholangiopancreatography. J Gastroenterol Hepatol 1994; 9(1): 55-9. 
20. Niederau C, Pohlmann U, Lübke H, Thomas L. Prophylatic antibiotic treatment in therapeutic or complicated diagnosis ERCP: results of a randomized controlled clinical study. Gastrointest Endosc 1994; 40(5): 533-7.

21. Bone RC, Balk RA, Cerra FB et al. ACCP/SCCM Consensus Conference: definitions for sepsis and organ failureand guidelines for the use of innovative therapies in sepsis. Chest 1992; 101(6): 1.644-55.

22. Dajani AS, Bisno AL, Chung KJ et al. Prevention of bacterial endocarditis: recommendations by the American Heart Association. J AMA 1990; 264(22): 2.919-22.

23. Shulman ST, Amren DP, Bisno AL et al. Prevention of bacterial endocarditis: a statement for health professionals by the committee on rheumatic fever and infective endocarditis of the council on cardiovascular disease in the young. Circulation 1984; 70(6): 1.123A-7A.

24. Fleischer D. Controversies, dilemmas, and dialogues: recommendations for antibi otic prophylaxis before endoscopy. AmJ Gastroenterol 1989; 84(12): 1.489-91.

25. Bianco J A, Pepe MS, Higano C et al. Prevalence of clinically relevant bacteremia after upper gastrointestinal endoscopy in bone marrow transplant recipients. AmJ Med 1990; 89(2): 134-6.

26. Durack DT. Prevention of infective endocarditis. N Engl J Med 1995; 332(1): 38-44.

27. Infection control during gastrointestinal endoscopy: guidelines for clinical application. Gastrointest Endosc 1988; 34(3): 37S-40S.

28. Sel by WS, Norton LD, Pokorny CS, Benn RA. Bacteremia and bacterascites after endoscopic sclerotherapy for bleeding esophageal varices and prevention by intravenous cefotaxime: a randomized trial. Gastroi ntest Endosc 1994; 40(6): 680-4.

29. Cohen LB, Korsten MA, Scherl EJ et al. Bacteremia after endoscopic injection sclerosis. Gastrointest Endosc 1983; 29(3): 198-200.

30. Raines DR, Branche WC, Anderson DL, Boyce J $r$ HW. The occurrence of bacteremia after esophageal dilatation. Gastrointest Endosc, 1975; 22(2): 86-7.

31. Botoman VA, Surawicz CM. Bacteremia with gastrointestinal endoscopic procedures. Gastrointest Endosc 1986, 32(5): 342-6.

32. Aronson MD, Bor DH. Blood cultures. Ann Intern Med 1987; 106(2): 246-53.

33. Greenwood D. Lacking blood for culture. Lancet 1993; 342 (8878): 1.006.

34. Ayliffe GAF. Principles of cleaning and disinfection. Which disinfectant? Gastroi ntest E ndosc Clin N Am 1993; 3(3): 411-29.

35. Siegel S. Estadística no paramétrica: aplicada a las ciências dela salud. México: Trillas, 1975.
36. Shorvon PJ , Eykyn SJ, Cotton PB. Progress report: gastrointestinal instrumentation, bacteraemia, and endocarditis. Gut 1983; 24(11): 1.078-93.

37. Washington II J A, IIstrup DM. Blood cultures: issues and controversies. Rev I nfect Dis 1986; 8(5): 792-802.

38. Spencer RC. Blood cultures: where do westand? J Clin Pathol 1988; 41(6): 668-70.

39. Mermel LA, Maki DG. Detection of bacteremia in adults: consequences of culturing an inadequate volume of blood. Ann Intern Med 1993; 119(4): 270-2.

40. Nolte FS, Williams J M, J erris RC et al. Multicenter clinical evaluation of a continuous monitoring blood culture system using fluorescent-sensor technology (Bactec 9240). J Clin Microbiol 1993; 31(3): 552-7.

41. Stevens M, Patel H, Walters A et al. Comparison of Sentinel and Bactec blood culture systems. J Clin Pathol 1992; 45(9): 815-8.

42. Sullivan NM, Tuck LK, Welty GS, Firstenberg-E den R. Evaluation of a new automated blood system. In: American Society of Microbi ol ogy General Meeting, New Orleans, 1992. Annals, American Society of Microbiology, 1992; 1-7.

43. Becton Dickinson Diagnostic Instrument Systems. Bactec Fluorescent series: user's manual. Maryland, 1993.

44. Wilson ML, Davis TE, Mirrett $S$ et al. Controlled comparison of the Bactec high-blood-volume fungal medium, Bactec Plus 26 aerobic blood culture bottle, and 10milliliter isolator blood culture system for detection of fungemia and bacteremia. J Clin Microbiol 1993; 31(4): 865-71.

45. Keeffe EB. Antibiotic prophylaxis: who, when, and how. Gastrointest Endosc Clin North Am 1993; 3(3): 431-45.

46. Eisenstein IB. Enterobacteriaceae. In Mandell GL, Bennett JE, Dolin R: Principles and practice of infectious diseases. New York, Churchill Livingstone, 1995; 1.964-80.

47. J ohnson CC, Tunkel AR. Viridans streptococci and groups $C$ and G streptococci. In Mandell GL, Bennett J E, Dolin R. Principles and practice of infectious diseases. New York, Churchill Livingstone, 1995; 1.845-61.

48. Moayyedi P, Lynch D, Axon A. Pseudomonas and endoscopy: review. Endoscopy 1994; 26(6): 554-8.

49. Struelens MJ , Rost F, Deplano A et al. Pseudomonas aeruginosa and Enterobacteriaceae bacteremia after biliary endoscopy: an outbreak investigation using DNA macrorestriction analysis. AmJ Med 1993; 95(5): 489-98.

50. Classen DC, J acobson J A, Burke J P, J acobson J T, Evans RS. Serious pseudomonas infections associated with endoscopic retrograde cholangiopancreatography. Am J Med 1988; 84(2): 590-6. 